\title{
New Paths to Social Justice and Recovering the Past
}

\author{
Holly Cusack-McVeigh \\ Indiana University-Purdue University Indianapolis
}

\begin{abstract}
On April 1, 2014, after months of investigative work and intensive planning, FBI agents knocked on the door of a private collector in rural Indiana. This was the start of a complex, multi-year investigation that resulted in the recovery of several thousand objects of cultural heritage. The collection, noted by scholars and agents alike for its "astounding global and temporal scope” included material culture from places as diverse as Colombia, China, Peru, Ecuador, Haiti, the Dominican Republic, Mexico, New Zealand, Papua New Guinea, Italy, Canada and the United States. What is most relevant, however, is the way the FBI has handled the case and why it may prove to be a replicable model. This article examines this unique, collaborative approach and its implications for future cases worldwide. It also highlights the moral issues surrounding cultural heritage protection and the shared sense of responsibility that this investigation engendered among stakeholders.
\end{abstract}

Keywords: Antiquities, Art Crime, Collaboration, Cultural Heritage, Ethics, Social Justice About the author: Dr. Holly Cusack-McVeigh is an Assistant Professor of Anthropology and Museum Studies at Indiana University-Purdue University Indianapolis. She holds appointments as a Public Scholar of Collections and Community Curation and Adjunct Assistant Professor of Native American \& Indigenous Studies. 
$<$ Insert Figure 1 here $>$

“Scholarship must at times proceed in an environment shaped by ambiguous evidence, polarized perspectives, and colliding visions of social justice” (Echo-Hawk 2002, v).

On April 1, 2014, after many months of investigative work and intensive planning, FBI agents finally knocked on the door of a private collector in rural Indiana. This was the start of a complex, multi-year criminal investigation that resulted in the recovery of several thousand objects of cultural heritage (Penner 2014). The collection, noted by scholars and agents alike for its “astounding global and temporal scope” (Mullins 2014) included material culture and human remains from places as diverse as Colombia, China, Peru, Ecuador, Haiti, the Dominican Republic (Hispaniola), Mexico, New Zealand, Papua New Guinea, Italy, Canada and the United States (see figure 1 for an example of the kinds of objects found). FBI agents from around the country arrived in Central Indiana to assist with this massive, unprecedented operation.

Leading this investigation were members of the FBI's Art Crime Team, a rapid deployment team of 16 special agents from around the country who have specialized training and expertise in fine arts, antiquities and cultural property. Founded in 2004 under the FBI's Art Theft Program, the Art Crime Team assists foreign law enforcement officials with art investigations throughout the world. The Art Crime Team also maintains the National Stolen Art File, a database of images and physical descriptions of stolen and recovered objects, an invaluable tool for agency investigators, museum professionals and scholars who work in the field of cultural heritage (FBI Federal Bureau of Investigation, 2016). 


\section{Confidentiality}

This article is written within the boundaries of a non-disclosure agreement. Playing a role in this ongoing investigation means that many of the concrete details must be left off the page until the case is legally resolved. The objects that are the center of investigation are remarkable, yet perhaps what is more interesting and relevant beyond this single collection is the way the FBI has handled this case and why it may prove to be a replicable model. Firstly, this article explores the unique, collaborative approach taken by the FBI and the implications this has for future cases worldwide. Secondly, it will address the moral issues surrounding cultural heritage protection and the shared sense of responsibility that this investigation engendered among diverse stakeholders.

\section{Challenges to Recovery}

From the onset, the lead agent on this case, Special Agent Timothy Carpenter, knew that he would need to tap into the skills, knowledge and expertise of those in the museum and academic worlds if he was to ensure a smooth operation and the safe recovery of the objects that were the center of this investigation. As a member of the Art Crime Team, he understood the importance of museum best practice. In fact, he routinely spoke to graduate students in the IUPUI Museum Studies Program about the Art Crime Team’s role in recovery cases, driving home the importance of routine inventories and the proper documentation of objects housed in museum collections. His vision for this operation was collaboration every step of the way, with museum professionals, representatives from local tribal communities, anthropologists, archaeologists and even museum studies graduate students. 
Early in the planning phase of this operation, the leadership acknowledged that there would be ongoing challenges to such a massive recovery effort. Planning teams spent months anticipating the numerous practical and legal issues associated with this case. The logistics and sheer number of people involved each day was tremendous. Two full shifts of 50 to 60 team members worked each day worked to locate, identify, number, record, photograph, wrap and transport the objects piece by piece. Museum professionals, Native American tribal representatives, anthropologists and graduate students, side-by-side with FBI agents, worked painstakingly to safely and efficiently recover this collection. Physical challenges ran the gamut from the physical strain of working long hours to contending with the aftermath of torrential rains. Object handlers at every stage in the recovery encountered issues that required quick thinking and ingenuity. FBI agents also recognized the value of having professionally trained collections and conservation experts on site throughout the recovery to address these ongoing challenges. Intellectual challenges ranged from complex legal issues to basic questions of how to track and number the objects. Museum methods required an object number, but FBI protocols demanded additional numbers for the collection of evidence.

\section{A Collaborative Approach}

This expansive collection recovered by the FBI would pique the interest of most, but the size and magnitude of the collection are not the most striking aspects of this case. What is most compelling about this case is the way the FBI approached it. Prior to the Indiana case, the Four Corners Case of 2009, then the nation's largest investigation of archaeological and cultural artifact thefts, was an operation that targeted "a network of individuals allegedly involved in the sale, purchase, and exchange of artifacts illegally taken from public or Indian lands in the Four

Corners region of the country” (U.S. Attorney’s Office, District of Utah 2009). That case led to 
felony charges against more than two dozen individuals in Utah, Colorado and New Mexico on charges of trafficking in artifacts. What makes the Indiana case unique is not solely the number or diversity of objects recovered, but the FBI's focus on these objects as items of cultural patrimony distinct from looted artworks and not reducible to evidence in an illegal trafficking case. This reflects not only a significant shift in terms of the agency's approach to recovering the past, but may also signal a change in public attitude.

The Indiana case is also notably different from the infamous Four Corners case in terms of the over-all approach. The Four Corners case played out like a true "sting operation," and although it also involved dozens of federal agents, it did not utilize the manpower and expertise of academicians, museum professionals and other cultural heritage experts who were on-site assisting federal agents in the actual identification and recovery of objects.

Federal investigations often end with the seizure of property or recovery of material evidence. This involves a system for processing and recording items, but it does not often entail a detailed analysis of how objects are handled and transported for safekeeping, nor does it account for the steps needed to establish a truly collaborative approach. From the very start, Agent Carpenter insisted that these objects of antiquity be handled with the utmost care. Looking to area museums throughout the Indianapolis area, we built a collaborative team of content experts and museum professionals from which to draw from throughout the planning stages, during the recovery phase, and well into the investigative research phase of the operation.

This collaborative effort also highlights the role and responsibility that museums have to become engaged in this kind of recovery. Collaboration relies on a mutual understanding and a shared sense of values. This kind of active participation on the part of museums has the potential 
to reshape the way we think about our shared heritage globally. Author Robert Janzen reminds us "all museums have the responsibility and the opportunity to become synthesizers, and foster an understanding of the interconnectedness of the problems we face both, environmental and social” (Janzen 2009, 166).

Responding to the call from the Indianapolis FBI field office, several Indianapolis area museums devoted time, resources and workforce in support of this recovery effort including the Eiteljorg Museum of American Indians and Western Art and the Indianapolis Museum of Art. On site, at any given time, were a mix of museum curators of history, curators of art, material culture specialists, collections managers, registrars, trained conservators and professional packers. Among the institutions involved, the Indianapolis Museum of Art was highly engaged from the start. The museum's leadership made a conscious choice to contribute both museum staff expertise and resources. Said one museum administrator:

As museum professionals many of us volunteered our time to assist the FBI with this case. We are passionate about protecting cultural property and making sure that the agents involved understood the fragility of the objects as well as the moral and ethical obligations involved with handling this material. Overall we learned a lot from one another and would welcome another opportunity to collaborate with them in the future [personal communication, March 16, 2015].

Another significant and central aspect of this collaborative approach revolves around the FBI's immediate and ongoing consultation with tribal nations in the US. Agents began reaching out to federally recognized tribes even before the weeklong recovery was complete. Meaningful 
consultation was achieved through transparency and respect. A commitment to ongoing meetings with tribal officials and Tribal Historic Preservation Officers (Advisory Council on Historic Preservation) has allowed for regular case updates over the past few years. It has also truly informed and shaped how the subsequent repatriation of objects and ancestral remains will take place. Following the weeklong recovery effort, FBI agents gave case briefings and held informational teleconference call meetings, under the title of "Moving Toward Respectful Repatriation,” for Tribal Historic Preservation Officers (THPOs ) and other tribal representatives. At one of the very first briefings in the summer of 2014, Agent Carpenter emphasized to the tribal nations "repatriation has always been our primary concern” (personal communication, June 2014).

The FBI has demonstrated respect for Native American traditions and values in many ways over the past few years. For example, the FBI agents adapted standard protocol of “evidence collection” by not processing the recovered human remains through a line where many hands recorded, documented, registered, packed and secured material culture objects for shipping. Instead the remains were documented and wrapped in situ to minimize handling.

When the last boxes of recovered human remains were finally loaded onto the truck, community elders from the Pokégnek Bodéwadmik (Pokagon Tribe) offered a prayer and assurances that the ancestors would be going home. In the midst of an immense "tear down" of domed tents and equipment -- generators and vehicle engines fell absolutely still for this time of remembrance. That following spring, in yet another case briefing with tribal representatives, Special Agent Andrew Northern concluded the meeting by stating: "We are very mindful that these are not just things, these are your ancestors” (personal communication, April 16, 2015). 
Museums have increasingly recognized the importance of honoring indigenous requests to make offerings in collection storage spaces. In fact, many museums accommodate tribal requests to "feed" collections and acknowledge that offerings made to sacred objects and ancestral remains vary from one to tribe to the next. Months before the start of the recovery operation, informal dialogue with Native community members in the region led to the suggestion that an offering of tobacco should be made if any ancestral remains were discovered on site. In fact, many tribal groups in the region use tobacco as a sign of respect for the dead. The Anishinaabe, the indigenous word for the Potawatomi (Neshnabek), Objibwe and Odawa people of the Great Lakes region, offer semah (tobacco) as a sign of respect whether harvesting plants, traveling across a body of water or working in a museum to bring ancestors back home. Miami scholar and Curator of Native American Art, History and Culture at the Eiteljorg Museum, Scott Shoemaker, reflecting on objects of his own cultural tradition now held in museum collections, describes the way his ancestors would have harvested the basswood tree to construct a medicine bag: “After placing ahseema - tobacco - down and saying the necessary prayer, she [the woman making the bag] proceeded to harvest strips” (Shoemaker 2011, 219). Many tribes throughout North America also observe this or similar practices such as making offerings of white sage. With guidance and assistance from Native community members, and following the lead of a growing number of museums to honor such requests, the FBI readily agreed to accommodate this practice.

At one point during those first arduous days in the recovery effort, an FBI agent turned to another and said quietly “Wait, don’t seal that box yet. It doesn’t have an offering.” At this juncture, none of individuals working the case had concrete knowledge or tangible forensic evidence to identify who these people were or if they were even of North American origin. In 
spite of this uncertainty, there was a shared sentiment among many that they needed to be treated with the same dignity afforded the dead of any group from the moment of discovery. All the while those involved in recovery, both Native and non-Native individuals, acknowledging that once identification was achieved representatives of specific cultural groups would enact their own cultural protocols for proper treatment of the dead.

While this practice has become much more widely accepted in the museum world, the immediate support from FBI agents, who were accustomed to seizing and processing evidence, was extraordinary. It may be surprising to many Native people and museum scholars that the suggestion that the Federal Bureau of Investigation follow the cultural protocols of tribal groups who call the region home was met with immediate acceptance. I have worked side-by-side with tribal leaders and community members on repatriation cases for over two decades. Particularly prior to and in the early years of NAGPRA (Native American Graves Protection and Repatriation Act) legislation (National Park Service, U.S. Department of the Interior 1990), as museum "visitors" we were sometimes "tolerated," but seldom treated with the respect that has characterized this case.

The passing of NAGPRA or the Native American Graves Protection and Repatriation Act a 1990 federal act, was a watershed event. For the first time, there was a solid legal mechanism for protecting Native American gravesites and facilitating the return of ancestral remains and cultural objects (including funerary objects, sacred objects and objects of cultural patrimony) to lineal descendants, and culturally affiliated Indian tribes and Native Hawaiian organizations. As of September 2014, the Federal Register notices indicate that a staggering 50, 518 individuals have been repatriated under NAGPRA. In addition to the ancestral remains, the National Park Service reports that some 1,185,948 associated funerary objects (objects are considered to be 
"associated" if the human remains with which the objects were placed are in the possession or control of a museum or Federal agency), 219,956 unassociated funerary objects, 4,914 sacred objects, 8,118 objects of cultural patrimony and another 1,624 objects that have been identified as both sacred and patrimonial have also been reclaimed under this federal act (http://www.nps.gov/nagpra/FAQ/INDEX.HTM ).

As a Federal law, NAGPRA has evolved over the years since its inception but, admittedly, does not remedy all transgressions. What is increasingly recognized is the foundational law upon which it was based, referred to as "the spirit of the law, (intent)" it is founded on common law. Sherry Hutt and Jennifer Riddle, in "The Law of Human Remains and Burials," state that this is "the foundation of law still in effect, the common law of the dead and burials." They go to say that this is "the law of organized communities, families, cultures, and social groups” (Cassman, Odegaard and Powell 2007, 223).

\section{A Global Responsibility}

At the heart of this case is an overarching theme that united the diverse on-site recovery teams from academia, the world of museology and the Federal Bureau of Investigation. Amid the tremendous logistical challenges, legal complexities (consideration of myriad national and international laws, and treaties), there was a general feeling that those working this case were "on moral high ground.” Why did so many of those involved with the case characterize their purpose in these terms? Reflecting back on public response to this case (both negative and positive), I am reminded of author Lynn Teague's discussion of the treatment of the dead and the way she skillfully employs a quote by John Rawls from his work, Theory of Justice. Rawls states that "Justice is the first virtue of social institutions, as truth is of systems of thought, ...Each 
person possesses an inviolability founded on justice that even the welfare of society as a whole cannot override” (Cassman, Odegaard and Powell 2007, 245). From a moral standpoint, then, justice is viewed as “fairness” (Rawls 1999; Cassmann, Odegaard and Powell 2007). Admittedly, concepts of fairness are hard to pin down, but imply freedom from bias or an injustice. This case is significant because it highlights a glaring injustice. We must ask ourselves whose ancestors have been the center of this kind of illegal and unethical activity for centuries. Why have Indigenous graves been viewed as "fair game” while European cemeteries (marked and unmarked) remain largely undisturbed? Clearly, the injustices of the living extend to the world of the dead.

We all have a social and moral responsibility to respond to these transgressions in some collective way. This inviolability or protection from assault should also extend to the dead. Most members of the recovery team came to this case with vast differences in training, background and life experiences but those differences paled by comparison to what united them. Simply put, they felt a sense of moral obligation and, perhaps a sense of moral satisfaction knowing that their actions addressed these injustices. This represents a shift in thinking about objects as merely evidence or scientific data, and could have a profound impact on how we think about and treat cultural property in the future.

Federal agents, tribal members, museum professionals, anthropologists and museum studies students all worked with a sense of purpose, but active participation by local museums also reflects this sense of obligation and their active engagement resonates with the idea that a “mindful museum can empower and honour all people in the search for a sustainable and just world” (Janzen 2009, 166). These are moral obligations rooted in social justice. In that sense, those who violate national and international laws regarding the protection of cultural heritage 
(including graves and other cultural sites) are also in violation of basic human rights. These are basic rights that should extend to not only the living but also the dead.

As a university professor, I have a responsibility to train my museum studies and anthropology students beyond the physical care of objects. I teach them to think about not only ancestral remains as animate and aware, but also to view the objects made and used by those ancestors in this way. Collections care goes far beyond the realm of cleaning, organizing, labeling and rehousing objects. "Care" of collections also means that we behave in a manner of respect. I directly involved my students in this case because this "field" experience nurtures the growth of self-reflective leaders in a way that classroom environments cannot replicate. Reflecting on own her involvement; one of my students noted the impact of seeing "that these objects matter to the Federal government, and that it is of national importance to have this cultural material returned." She continued, "I think wow, this is significant, and although my role in it may be small, I am part of something much bigger” (personal communication, January 29, 2016).

\section{Conclusion}

Now into the third year of this ongoing investigation, the FBI continues to dedicate significant resources to determine the provenance of each object while simultaneously maintaining open dialogue and transparency with nations (both domestic and foreign) to ensure the eventual repatriation of those individuals and the objects improperly acquired or in violation of United States or international law. What remains to be seen are the long-term lessons that may come from this case and the critical questions it has raised. This landmark case, with its unique collaborative approach, can serve as a replicable model for other FBI agents who investigate 
future antiquities cases. The key here is leadership and a need to build strong, collaborative relations across institutions that share similar values and a common understanding in defense of cultural heritage. It also highlights another significant point about leadership. Simply put individuals matter. Agent Carpenter was able to achieve this significant collaboration because of his continued efforts to reach out and network with museums and universities long before the case ever came to light.

This case certainly reflects a paradigm shift, and while some of that is grounded in the policy legally required by NAGPRA, it may also signal a general societal shift in thinking. However, there is still a great deal of work to be done. Academicians who already define these violations as "unethical," must also begin to overtly acknowledge that such recovery efforts move us closer to social justice. Museums must respond to these calls for collaboration as they seek ways to become more relevant to their stakeholders and potentially new audiences. By embracing these kinds of collaborative efforts museums also send a powerful message about our shared sense of responsibility in protecting cultural heritage beyond the walls of the museum. This case stands to help those who work to protect cultural heritage in conveying an important message to those who exploit it. As human beings, we all have a moral obligation to respond to this case and others like it. The plundering of sites, desecration of graves and destruction of objects is not a new conundrum for those working in the field of cultural heritage. What is new is this innovative, collaborative approach, which holds great promise for future efforts to safe guard sites and cultural heritage worldwide. 


\section{References}

Advisory Council on Historic Preservation. “Tribal Historic Preservation Officers (THPOs).” Accessed March 22, 2015. http://www.achp.gov/thpo.html.

Echo-Hawk, Walter. 2002. Keepers of Culture: Repatriating Cultural Items under the Native American Graves Protection and Repatriation Act. Denver: Denver Art Museum.

FBI Federal Bureau of Investigation. 2016 “Art Crime Team National Stolen Art File.” Accessed February 11, 2016. http://www.fbi.gov/about-us/investigate/vc_majorthefts/arttheft/artcrime-team.

Hutt, Sherry, and Jennifer Riddle. 2007. “The Law of Human Remains and Burials.” In Human Remains: Guide for Museums and Academic Institutions, edited by Vicki Cassman, Nancy Odegaard and Joseph Powell, 223-243. New York: AltaMira Press.

Janes, Robert R. 2009. Museums in a Troubled World: Renewal, Irrelevance or Collapse. New York: Routledge.

Mullins, Paul. 2014. “The Morality of Property and Cultural Patrimony.” Accessed April 12, 2015. https://paulmullins.wordpress.com/2014/04/05/the-morality-of-property-andcultural-patrimony/.

National Park Service, U.S. Department of the Interior. "National NAGPRA Native American Graves Protection and Repatriation Act, 25 U.S.C. 3001 et seq. [Nov. 16, 1990]” Accessed September 5, 2015. http://www.nps.gov/nagpra/.

Penner, Diana. 2014. “Thousands of artifacts removed from rural Indiana home.” Indy Star, April 2. Accessed April 7, 2015. 
http://www.indystar.com/story/news/crime/2014/04/02/fbi-seizing-artifacts-rural-indianahome/7210675/.

Rawls, John. 1999. A Theory of Justice. Cambridge: Belknap Press.

Shoemaker, Scott M. 2011. “Trickster Skins: Narratives of Landscape, Representation, and the Miami Nation.” PhD diss., Department of American Indian Studies, University of Minnesota.

Teague, Lynn S. 2007. “Respect for the Dead, Respect for the Living.” In Human Remains: Guide for Museums and Academic Institutions, edited by Vicki Cassman, Nancy Odegaard and Joseph Powell, 245-259. New York: AltaMira Press.

U.S. Attorney’s Office, District of Utah. “Arrests Made in Operation Targeting Network Selling Stolen Native American Artifacts Two-Year Undercover Operation in Four Corners Region Leads to Nation's Largest Investigation of Artifacts Taken from Public, Native American Lands.” Accessed March 25, 2015. http://www.fbi.gov/saltlakecity/pressreleases/2009/slc061009.htm. 